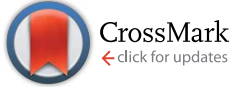

Cite this: RSC Adv., 2017, 7, 5055

Received 1st December 2016

Accepted 5th January 2017

DOI: 10.1039/c6ra27631h

www.rsc.org/advances

\section{A theoretical study on the electronic and photophysical properties of two series of iridium(III) complexes with different substituted $\mathrm{N}^{\wedge} \mathrm{N}$ ligand $\uparrow$}

\begin{abstract}
Xiaohong Shang, ${ }^{\text {*a }}$ Deming Han, ${ }^{\mathrm{b}}$ Mei Liu ${ }^{\mathrm{a}}$ and Gang Zhang ${ }^{\mathrm{c}}$
A density functional theory/time-depended density functional theory has been applied to explore the geometrical, electronic and photophysical properties of the recently reported pyrazolyl-pyridine- or triazolyl-pyridine-containing iridium(III) complexes 1 and 2. The calculated absorption and emission wavelengths are in agreement with experimental data. Based on complexes 1 and 2, two series of Ir(III) complexes $1 a-1 c$ and $2 a-2 c$ with different $N^{\wedge} N$ ligand have been designed. It is found that the photophysical properties of these complexes are greatly affected by the properties of the adopted ligands. From 2 to 2c, the ancillary ligands based on a bis(triazolyl-pyridine) moiety with a $m$-phenylene spacer group render an increase of the HOMO-LUMO energy gap, but relatively weak absorption intensities. It is believed that the larger ${ }^{3} \mathrm{MC} / \mathrm{d}-\mathrm{d} \rightarrow{ }^{3} \mathrm{MLCT} / \pi-\pi^{*}$ energy gap, higher $\mu_{\mathrm{S}_{1}}$ and MLCT \% values, as well as the smaller $\Delta E_{\mathrm{S}_{1}-\mathrm{T}_{1}}$ for $2 \mathrm{~b}$ and $2 \mathrm{c}$, are good indications for the higher quantum efficiency compared with that of experimental structure 2. Therefore, the newly designed complexes $2 \mathrm{~b}$ and $2 \mathrm{c}$ are expected to be highly efficient deep-blue emitters for OLEDs application.
\end{abstract}

\section{Introduction}

In extensive and on-going research into the organic lightemitting diodes (OLEDs), particular focus has been directed towards phosphorescent emitting materials due to their potential $100 \%$ internal quantum efficiency and hence the strong possibility of developing more efficient OLEDs than fluorescent emitting material based OLEDs. ${ }^{1,2}$ Strong spin-orbit coupling induced by these central transition metal atoms promotes an efficient singlet/triplet intersystem crossing, and harnesses both the singlet and triplet excitons generated from electroluminescence excitation. Homoleptic and heteroleptic $\operatorname{Ir}\left(\right.$ III) complexes bearing the main $\mathrm{C}^{\wedge} \mathrm{N}$ ligand have attracted much attention due to their unique photophysical properties, such as higher phosphorescence quantum efficiency and easy tuning emission energies from blue to red through substituent changes of the main ligand. ${ }^{3,4}$ In particular, iridium compounds with green and red emission have been successful as triplet emitters in phosphorescence organic light-emitting diodes (PHOLEDs). ${ }^{5}$ Highly efficient blue phosphorescent iridium

${ }^{a}$ College of Chemistry and Life Science, Changchun University of Technology, Changchun 130012, P. R. China. E-mail: shangxiaohong58@aliyun.com; Tel: +86 18686507982

${ }^{b}$ School of Life Science and Technology, Changchun University of Science and Technology, Changchun 130022, P. R. China

'Institute of Theoretical Chemistry, Jilin University, Changchun 130023, P. R. China $\dagger$ Electronic supplementary information (ESI) available. See DOI: $10.1039 / \mathrm{c} 6 \mathrm{ra} 27631 \mathrm{~h}$ complexes are of particular importance because they are essential part in the development of energy-saving full-colour displays and solid state lighting. ${ }^{6-10}$ However, the number of suitable blue iridium compounds for OLEDs applications is very limited compared to green and red iridium phosphors. ${ }^{11}$

The tuning of emission colors over the entire visible spectra has been achieved by ingenious modification of the cyclometalated and/or ancillary ligands. ${ }^{12-15}$ The representative blue Ir(III) phosphors include FIrpic, ${ }^{16}$ FIr6, ${ }^{17}$ and FIrtaz, ${ }^{18}$ which consist of at least one difluorophenyl-pyridine-based ligand (dfppy), one of the well-known ligands for providing short emission wavelengths. Although the modifications of ligands have produced a hypsochromic shift versus the emission of FIrpic, their significant lowering of the quantum yield has hampered the fabrication of the highly efficient, true-blue phosphorescent OLEDs.

Recently, Sykes, D. et al. synthesized that blue $\operatorname{Ir}(\mathrm{III})$ complexes ${ }^{19} 1$ and 2 (Fig. 1).

The complexes form two pairs: in both $\mathbf{1}$ and 2, the phenylpyridine ligands are attached to $\operatorname{Ir}(\mathrm{III})$ contains two $\mathrm{F}$ atom substituents at positions 2 and 4 of the phenyl ring, but the bisbidentate ligand contains pyrazolyl-pyridine chelating units in $\mathbf{1}$ is separated by a biphenyl spacer or based on a bis(triazolylpyridine) ligand with a $m$-phenylene spacer group in 2 . In this work, based upon the experimental complexes 1 and 2, we designed two series of derivatives $1 \mathbf{a}-\mathbf{1 c}$ and $\mathbf{2 a - 2 \mathbf { c }}$ by a systematic substitution by $-\mathrm{F}$ or $-\mathrm{CF}_{3}$ at " $R_{1}$ and $R_{2}$ " positions on the ancillary $\left(\mathrm{N}^{\wedge} \mathrm{N}\right)$ and cyclometalated $\left(\mathrm{C}^{\wedge} \mathrm{N}\right)$ ligands, respectively. The spectroscopic properties and electron structures are crucial 


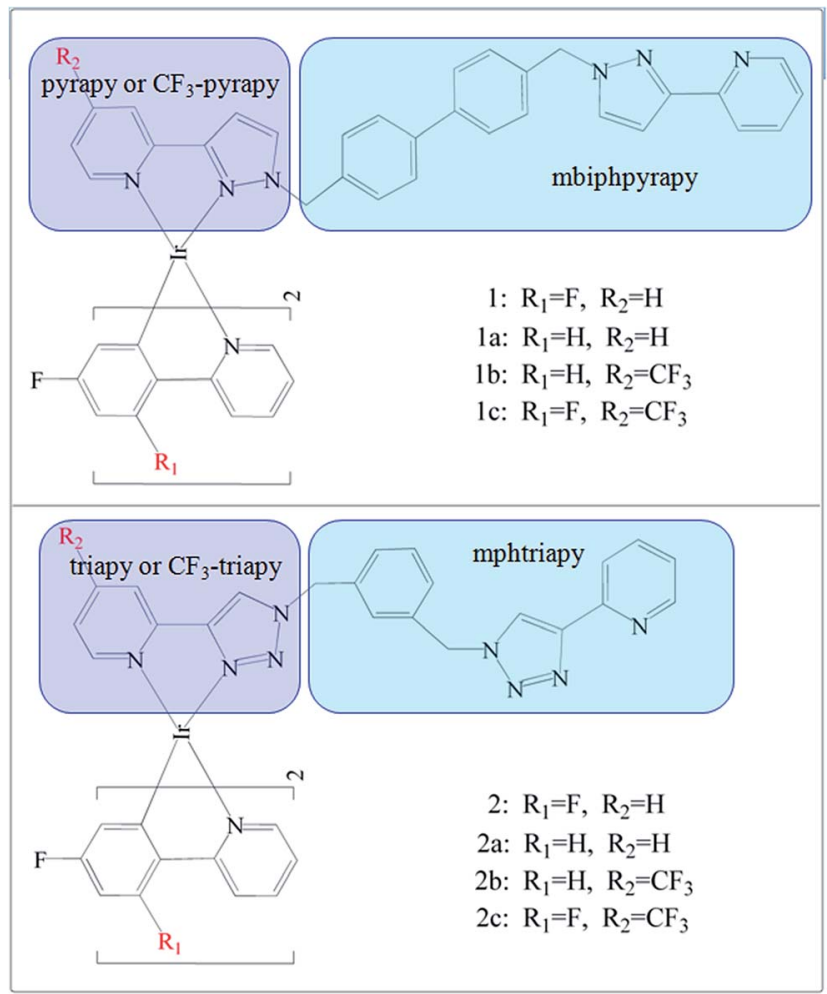

Fig. 1 Schematic structures of the investigated complexes.

to gain insight into emission color change with different ancillary ligands. The main objective of this work is to explore the strategy of affecting the phosphorescent properties of these studied complexes. In particular, the influence of the employed ligands with the different electron-withdrawing abilities on quantum efficiency are also discussed, which will be of great benefit for designing novel, high efficient blue-emitting $\operatorname{Ir}($ III) complexes.

\section{Computational details}

Density functional theory (DFT) ${ }^{20}$ method with hybrid HartreeFock/density functional model (PBE0) based on the PerdewBurke-Erzenrhof $(\mathrm{PBE})^{21,22}$ together with the 6-31G* basis set ${ }^{23,24}$ for $\mathrm{C}, \mathrm{H}, \mathrm{N}$ and $\mathrm{F}$ atoms and the "double- $\zeta$ " quality LANL2DZ basis set for the Ir element. An effective core potential (ECP) replaces the inner core electrons of Ir leaving the outer core $\left[(5 \mathrm{~s})^{2}(5 \mathrm{p})^{6}\right]$ electrons and the $(5 \mathrm{~d})^{6}$ valence electrons of $\operatorname{Ir}(\mathrm{III})$. Singlet and triplet excitation energies have been obtained with the time dependent DFT (TDDFT) (TD-PBE0) formalism based on $S_{0}$ geometries, while the $S_{1}-T_{1}$ energy gap $\left(\Delta E_{S_{1}-T_{1}}\right)$ was calculated considering the fixed triplet molecular geometry. Solvent effects were taken into account in DFT and TDDFT calculations using the polarized continuum model (PCM) $)^{25-28}$ in dichloromethane $\left(\mathrm{CH}_{2} \mathrm{Cl}_{2}\right)^{19}$ media. All calculations were carried out with the default convergence criteria. The calculations mentioned above were done with the help of the D01 revision of the Gaussian 09 program package ${ }^{29}$ Gausssum 2.5 (ref. 30) being used for UV/Vis spectra analysis and Gabedit 2.3.9 user interface ${ }^{31}$ for structures and orbitals manipulations.

\section{Results and discussion}

\subsection{Molecular geometries in ground and lowest triplet states}

To investigate the solvent effect, the ground-state $\left(\mathrm{S}_{0}\right)$ and triplet-state $\left(\mathrm{T}_{1}\right)$ geometry optimization of all studied complexes were also performed within the self-consistent reaction field (SCRF) theory using the polarized continuum model (PCM) in dichloromethane $\left(\mathrm{CH}_{2} \mathrm{Cl}_{2}\right)$ media to model the interaction with the solvent. Structural drawings of the investigated complexes 1-2c (1-2c indicates 1-1c and 2-2c, which are the same hereafter) are depicted in Fig. 1. Moreover, the optimized $S_{0}$ geometrical structure of $\mathbf{1}$ is shown in Fig. 2, along with the numbering of some key atoms.

To gain a better understanding of the structural relaxation from the $S_{0}$ to $T_{1}$ state, the selected optimized geometry parameters for the $S_{0}$ and $T_{1}$ states of 1-2c are summarized in Table 1 together with the X-ray crystal structure data of $\mathbf{1}$ and $\mathbf{2}$.

In order to check the reliability of the method used in the present calculation, B3LYP ${ }^{32,33}$ and PBE0 were also performed on the optimization of the $\mathrm{S}_{0}$ geometries for $\mathbf{1}$ and $\mathbf{2}$ based on their single-crystal X-ray structures ${ }^{19}$ respectively. The results showed that the PBE0 functional has the best performance.

It can be seen that all complexes studied here adopt a pseudo-octahedral coordination geometry, similar to most reported Ir(III) complexes owing to the $\mathrm{d}^{6}$ configuration of the Ir(III) center. Table 1 also shows that the change of Ir-N3 and Ir$\mathrm{N} 4$ bond lengths for complexes $\mathbf{1 b}, \mathbf{1 c}, \mathbf{2 b}$ and $\mathbf{2 c}$ has a significant influence on the ancillary ligand $\left(\mathrm{N}^{\wedge} \mathrm{N}\right)$, which is probably due to the electron-withdrawing effect of $-\mathrm{CF}_{3}$ group and the extended $\pi$-conjugation. This may increase the $\pi$-accepting ability of pyridyl, and therefore, lead to the strengthened metalligand interaction. For all complexes, the metal-ligand bond distances (Ir-C1, Ir-C2, Ir-N1 and Ir-N2) show little change with the change of the cyclometalated ligands $\left(\mathrm{C}^{\wedge} \mathrm{N}\right)$. Additionally, the Ir-C bonds lengths are generally shorter than the Ir-N ones, which can be attributed to the stronger ligand field of $\mathrm{NHC}$ ligands compared to the $\mathrm{N}^{\wedge} \mathrm{N}$ ligand. Moreover, the Ir-C2 bond lengths are slightly changed (within $0.01 \AA$ ) compared with the Ir-C1 ones, while the Ir-N1 and Ir-N2 bond lengths are significantly shortened in comparison to those of Ir-N3 and Ir-N4. This indicates the strong interaction between the $\operatorname{Ir}(\mathrm{III})$ center and the $\mathrm{C}^{\wedge} \mathrm{N}$ ligands, which may also increase the probability of charge transfer from metal to $\mathrm{C}^{\wedge} \mathrm{N}$ ligands in

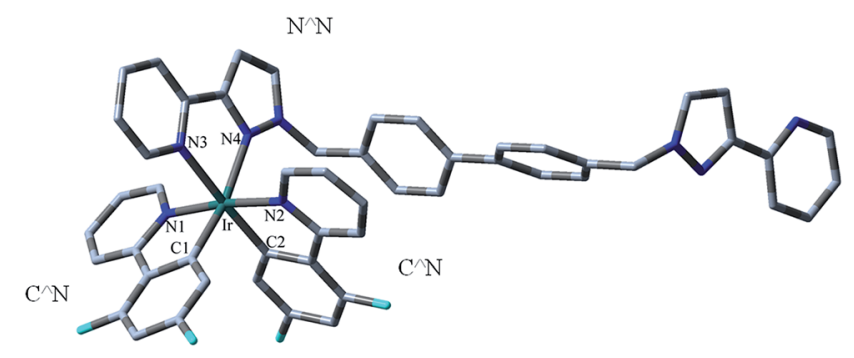

Fig. 2 Optimized structure of 1 in the ground state. 
Table 1 Main optimized geometry parameters of the investigated complexes in the ground and the lowest lying triplet states, together with the experimental values ${ }^{a}$

\begin{tabular}{|c|c|c|c|c|c|c|c|c|}
\hline & $\mathrm{S}_{0}$ exptl/PBE0/B3LYP & $\mathrm{T}_{1}$ & $\mathrm{~S}_{0}$ & $\mathrm{~T}_{1}$ & $\mathrm{~S}_{0}$ & $\mathrm{~T}_{1}$ & $\mathrm{~S}_{0}$ & $\mathrm{~T}_{1}$ \\
\hline Ir-N1 & $2.053 / 2.057 / 2.085$ & 2.031 & 2.059 & 2.055 & 2.060 & 2.052 & 2.058 & 2.050 \\
\hline Ir-N2 & $2.047 / 2.054 / 2.079$ & 2.062 & 2.054 & 2.042 & 2.055 & 2.052 & 2.053 & 2.045 \\
\hline Ir-C1 & $1.991 / 1.995 / 2.012$ & 1.978 & 1.996 & 1.991 & 1.996 & 1.978 & 1.995 & 1.983 \\
\hline Ir-N4 & $2.158 / 2.196 / 2.252$ & 2.201 & 2.199 & 2.149 & 2.202 & 2.178 & 2.201 & 2.174 \\
\hline \multicolumn{9}{|c|}{ Bond angle/deg } \\
\hline $\mathrm{N} 1-\mathrm{Ir}-\mathrm{C} 1$ & $80.8 / 80.5 / 80.1$ & 81.7 & 80.4 & 80.9 & 80.4 & 81.2 & 80.5 & 81.0 \\
\hline N1-Ir-N2 & 175.2/173.4/173.4 & 174.1 & 173.3 & 175.4 & 173.1 & 177.2 & 173.3 & 176.0 \\
\hline \multirow[t]{2}{*}{ N1-Ir-N3 } & $86.9 / 87.3 / 87.4$ & 86.7 & 87.4 & 85.2 & 87.4 & 86.7 & 87.2 & 85.9 \\
\hline & \multicolumn{2}{|l|}{2} & \multicolumn{2}{|l|}{$2 \mathbf{a}$} & \multicolumn{2}{|l|}{$2 \mathbf{b}$} & \multicolumn{2}{|l|}{$2 \mathrm{c}$} \\
\hline \multicolumn{9}{|c|}{ Bond length/Å } \\
\hline Ir-N1 & $2.044 / 2.053 / 2.080$ & 2.027 & 2.055 & 2.033 & 2.056 & 2.053 & 2.055 & 2.051 \\
\hline $\mathrm{Ir}-\mathrm{N} 2$ & $2.059 / 2.057 / 2.081$ & 2.066 & 2.057 & 2.065 & 2.057 & 2.052 & 2.055 & 2.051 \\
\hline $\mathrm{Ir}-\mathrm{C} 1$ & $2.005 / 1.997 / 2.015$ & 1.977 & 1.999 & 1.976 & 2.000 & 1.974 & 2.000 & 1.974 \\
\hline $\mathrm{Ir}-\mathrm{C} 2$ & $2.002 / 2.000 / 2.015$ & 1.996 & 2.000 & 1.996 & 2.001 & 1.987 & 1.999 & 1.989 \\
\hline $\mathrm{Ir}-\mathrm{N} 3$ & $2.176 / 2.209 / 2.261$ & 2.233 & 2.209 & 2.232 & 2.206 & 2.152 & 2.204 & 2.143 \\
\hline $\mathrm{Ir}-\mathrm{N} 4$ & $2.116 / 2.158 / 2.192$ & 2.164 & 2.158 & 2.164 & 2.151 & 2.144 & 2.147 & 2.145 \\
\hline \multicolumn{9}{|c|}{ Bond angle/deg } \\
\hline N1-Ir-C1 & $80.7 / 80.4 / 80.2$ & 81.8 & 80.4 & 81.9 & 80.4 & 81.2 & 80.4 & 81.1 \\
\hline N1-Ir-N2 & 171.9/173.5/173.7 & 174.4 & 173.2 & 174.3 & 173.1 & 177.1 & 173.3 & 176.9 \\
\hline
\end{tabular}

1-2c. The changes of the calculated coordination bond angle are minor (less than $1.0^{\circ}$ ) from 1 and 2 to $1 \mathrm{a}-1 \mathrm{c}$ and $2 \mathrm{a}-2 \mathrm{c}$ (Table 1).

Since both the $S_{0}$ and $T_{1}$ states are involved in the phosphorescence process, it is essential to discuss the geometric structures in the $\mathrm{T}_{1}$ state of the studied complexes. For the lowest lying excited state $T_{1}$, a relatively large lengthening of $0.006-0.024 \AA$ is detected for the Ir-N3 and Ir-N4 for 1, 2 and $2 \mathrm{a}$ in the $\mathrm{T}_{1}$ states corresponding to the $\mathrm{S}_{0}$ states, which weakens the interaction between the $\mathrm{N}^{\wedge} \mathrm{N}$ ligand and metal. Meanwhile, the Ir-N1, Ir-N2 (except for 1, 2 and 2a), Ir-C1 and Ir-C2 bond lengths are significantly shortened compared with their corresponding ground state, resulting in the strengthened interaction between metal Ir and $\mathrm{C}^{\wedge} \mathrm{N}$ ligands in $\mathrm{T}_{1}$ state, which suggests that the $\mathrm{C}^{\wedge} \mathrm{N}$ ligands are more strongly bound to the $\operatorname{Ir}(\mathrm{III})$ than the $\mathrm{N}^{\wedge} \mathrm{N}$ ligand, thus resulting in it having the most involvement in excited states and might consequently result in the decrease of metal-centered (MC) nonradiative emission and enhancement of radiative deactivation compared with 1, 2 and $2 \mathbf{a}$.

\subsection{Frontier molecular orbitals analysis}

In order to gain in-depth information regarding the photophysical behavior of all the named complexes, it is imperative to further analyse the frontier molecular orbitals (FMOs), especially the highest occupied and lowest unoccupied molecular orbitals (HOMO and LUMO). The contour plots of the HOMO and LUMO and energy levels for these complexes are shown in Fig. 3.

Furthermore, more detailed description of the molecular orbitals is collected in ESI Tables S1-S8. $\dagger$

Fig. 3(a) shows that 1-1c have the similar FMOs. The HOMO is predominantly localized on $\pi$ (mbiphpyrapy) moieties, while the LUMO is mainly contributed by $\pi^{*}$ (pyrapy) (for $\mathbf{1}$ and 1a) and $\pi^{*}\left(\mathrm{CF}_{3}\right.$-pyrapy) (for $\mathbf{1 b}$ and $\left.\mathbf{1 c}\right)$. Taking $\mathbf{1}$ as an example, the HOMO is composed of $100 \% \pi$ (mbiphpyrapy), while the LUMO has $95 \% \pi^{*}\left(\mathrm{CF}_{3}\right.$-pyrapy). However, the change of the ancillary ligands for complexes 2-2c has a significant influence on the electron density distributions and FMO energy levels as shown in Fig. 3(b). It can be seen from Fig. 3(b) that, for complexes 2$2 \mathrm{c}$, the HOMO are both mainly localized on the $\pi$ orbitals of the cyclometalated $\mathrm{C}^{\wedge} \mathrm{N}$ ligands and $\mathrm{d}^{6}$ metal center of iridium, and the LUMO mainly reside on the $\pi^{*}$ (triapy) (for 2 and $2 \mathrm{a}$ ) and $\pi^{*}\left(\mathrm{CF}_{3}\right.$-triapy) (for $\mathbf{2 b}$ and $\left.2 \mathbf{c}\right)$ moieties. For the 2-2c complexes, d orbitals of Ir contribute much to the HOMO while contributing little to those LUMO, probably suggesting remarkable MLCT character for the excited states, whereas for 1-1c, the 

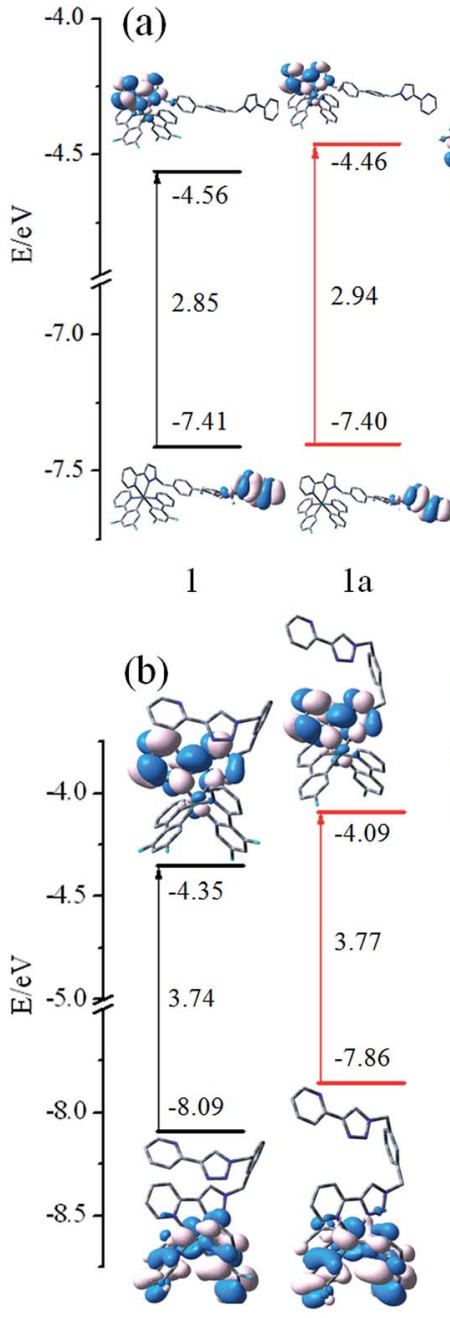

2
$1 \mathrm{a}$

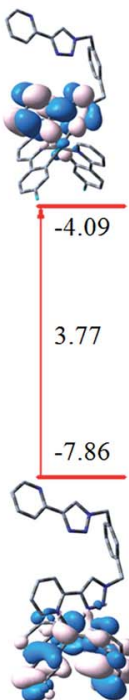

$2 \mathrm{a}$

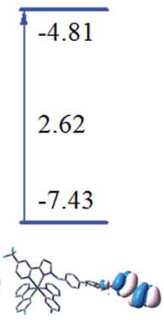

$1 \mathrm{~b}$

$2 b$
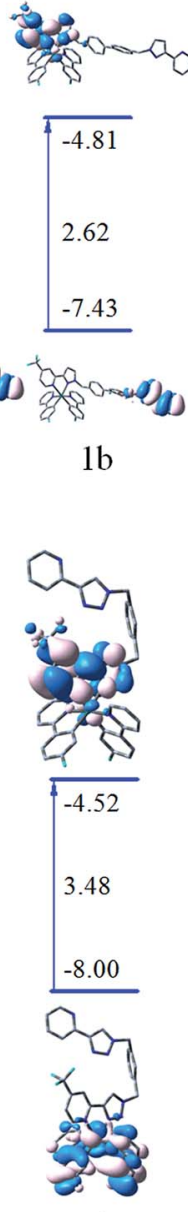

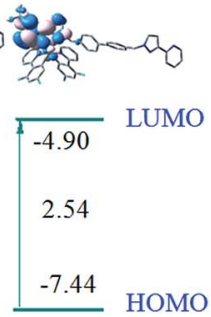

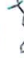

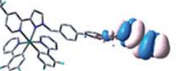

$1 \mathrm{c}$
Fig. 3 Energy level, energy gaps (in eV), and orbital composition distribution of HOMO and LUMO for the studied complexes.

participation of the d(Ir) orbital to HOMO and LUMO is vanished (Tables S1-S4†), it is anticipated that 1-1c probably has obvious LLCT (ligand-to-ligand charge transfer) and ILCT (intraligand charge transfer) charge transfer character.

Fig. 3 shows that more $-\mathrm{F}$ and $-\mathrm{CF}_{3}$ groups on the complexes can efficiently stabilize the HOMO and LUMO energy levels and reduce the HOMO-LUMO energy gaps. The LUMO is destabilized more markedly than that of the HOMO. In addition, it is notable that the energy gap of 1-1c complexes are different from those of 2-2c, which is probably caused by the different degree of decrease in the HOMO and LUMO energy levels. Thus, making comparisons between 1-1c and 2-2c, it can be suspected that the change of the ancillary ligand for complexes 22c may make the emission band shift in the blue direction. This means that the selected ligand is very important because their HOMO and LUMO spatial distribution are closely related to the HOMO and LUMO energy levels of the complexes and will influence the emission spectra significantly. Besides, the energy gap of $\mathbf{2 b}$ is calculated to be $3.48 \mathrm{eV}$, which is about $0.29 \mathrm{eV}$ lower than that of 2a. Simultaneously, 2c has the deepest HOMO and LUMO energy level among the studied complexes.

\subsection{Absorption in dichloromethane}

The absorption spectra of the eight guest complexes 1-2c in $\mathrm{CH}_{2} \mathrm{Cl}_{2}$ solvent through TDDFT/PBE0 methods have been investigated, and the corresponding results are sketched in Fig. 4.

Additionally, to get the specific transition process, the related wavelengths, oscillator strengths, compositions, and transition natures of the main peaks for 1-2c are listed in Tables S9 and S10.†

As seen from Fig. 4, complexes 1-1c have the similar absorption curves in band locations in the ultraviolet region between 240-290 $\mathrm{nm}$. The relatively weak absorption bands in the range 230-270 $\mathrm{nm}$ for 2-2c are blue-shifted by about $15 \mathrm{~nm}$ compared with that of 1-1c. It can also be seen from Fig. 4 that the most intense absorption bands of 1 is about $20 \mathrm{~nm}$ redshifted compared with that of 2 , which can be rationalized by the fact that it has the relatively small HOMO-LUMO energy gap. In the experimental spectra, lowest-lying singlet absorptions peaks for 1 and 2 are located at around 363 and $361 \mathrm{~nm},{ }^{19}$ respectively, while the TDDFT calculations at 366 and $371 \mathrm{~nm}$ (Tables S9 and S10 $\dagger$ ) agree well with the experimental data. Although, TDDFT is believed to give substantial errors for the excitation energies of charge-transfer excited states, ${ }^{34}$ in the present calculations, to a certain degree, it could predict the photophysical behavior of these Ir(III) complexes.

Complexes $\mathbf{1}$ and $\mathbf{1 a}(\mathbf{1 b}$ and $\mathbf{1 c})$ show very similar patterns in their absorption curves, indicating that the addition of a fluorosubstituent in the phenyl of $\mathrm{C}^{\wedge} \mathrm{N}$ ligands causes little influence on the absorption spectra of $\mathbf{1}$ and $\mathbf{1 b}$, the same conclusion can also be applied to 2 and $2 \mathbf{a}\left(2 \mathbf{b}\right.$ and $2 \mathbf{c}$ ). Their lowest $S_{0} \rightarrow S_{1}$ excited states are mainly contributed by the transition HOMO $\rightarrow$ LUMO (96\% in composition) and located at 366 and $371 \mathrm{~nm}$ for parent complexes $\mathbf{1}$ and $\mathbf{2}$ with negligible oscillator

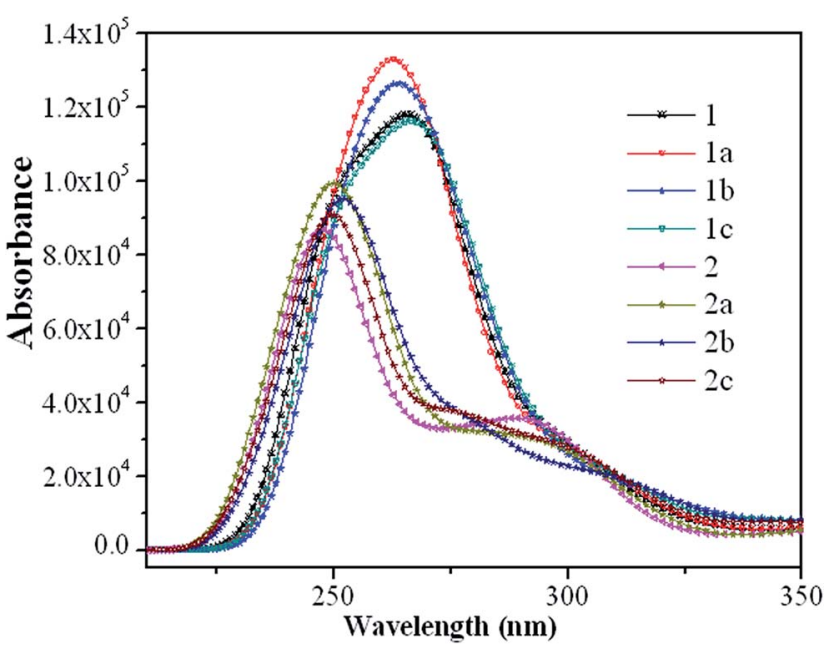

Fig. 4 Simulated absorption spectra for the studied complexes in $\mathrm{CH}_{2} \mathrm{Cl}_{2}$ media. 
strengths, both of which are characterized as ILCT $[\pi(\mathrm{mbiph}-$ pyrapy) $\rightarrow \pi^{*}$ (pyrapy)] and MLCT(metal-to-ligand charge transfer $) / \mathrm{LLCT}\left[\mathrm{d}(\mathrm{Ir})+\pi\left(\mathrm{C}^{\wedge} \mathrm{N}\right) \rightarrow \pi^{*}\right.$ (triapy) $]$ characters, respectively. The transition configuration of $\mathrm{HOMO}-7 \rightarrow$ LUMO contributes to the $269 \mathrm{~nm}$ absorption with the largest oscillator strength for $\mathbf{1}$, which is described as the $\left[\pi\left(\mathrm{C}^{\wedge} \mathrm{N}\right) \rightarrow\right.$ $\pi *$ (pyrapy)] transition. The HOMO-1 $\rightarrow$ LUMO+2 excitation is the main configuration for $293 \mathrm{~nm}$ absorption of 2 with the mixed transition characters of LLCT/ILCT. For 1-1c, the transitions with the largest oscillator strengths are located at around $270 \mathrm{~nm}$, and have the transition characters of $\left[\pi\right.$ (mbiphpyrapy) $\left.\rightarrow \pi^{*}\left(\mathrm{C}^{\wedge} \mathrm{N}\right)\right] / \mathrm{LLCT}$, with the exception of $\mathbf{1}$ and 1a, which is mainly the transition localized on the section $\left[\pi\left(\mathrm{C}^{\wedge} \mathrm{N}\right) \rightarrow \pi^{*}\right.$ (pyrapy) $] /$ LLCT and $[\pi($ mbiphpyrapy $) \rightarrow$ $\pi^{*}$ (mbiphpyrapy)]/ILCT (Table S9, ESI $\dagger$ ), respectively. Besides, 2-2c share the similar pattern in the absorption curves, which once again confirm that the introduction of different substituent causes little influence on the absorption properties.

\subsection{Phosphorescence in $\mathrm{CH}_{2} \mathrm{Cl}_{2}$ media}

In order to further confirm the nature of the lowest-lying emission transitions for the studied complexes, the phosphorescent emission energies at their optimized $\mathrm{T}_{1}$ geometries were calculated by the TDDFT/M062X method with PCM in the $\mathrm{CH}_{2} \mathrm{Cl}_{2}$ media. To obtain reliable results, six TDDFT functionals (M062X, M052X, PBE0, B3LYP, CAM-B3LYP and BP86) were examined here (Table S11†). Clearly, the emission wavelength are dramatically overrated when performed using M052X, PBE0, B3LYP, CAM-B3LYP and BP86 functionals, while the M062X gives more favorable results for parent complexes $\mathbf{1}$ and 2 . The calculated lowest energy emissions for 1 and 2 at M062X level are localized at 479 and $466 \mathrm{~nm}$, deviating from measured values by 25 and $22 \mathrm{~nm}$. Hence, the M062X functional was employed to predict the emission spectra for other complexes.

The calculated emission wavelength, configuration, transition nature, and the available experimental values are listed in Table 2.

Table 2 Calculated phosphorescent emission of the studied complexes in $\mathrm{CH}_{2} \mathrm{Cl}_{2}$ media at the TDDFT/M062X level, together with the experimental values ${ }^{a}$

\begin{tabular}{|c|c|c|c|c|}
\hline & $\lambda(\mathrm{nm})$ & Configuration & Character & Exptl \\
\hline 1 & 479 & $\mathrm{~L} \rightarrow \mathrm{H}(81 \%)$ & $\pi^{*}\left(\mathrm{~N}^{\wedge} \mathrm{N}\right) \rightarrow \pi\left(\mathrm{N}^{\wedge} \mathrm{N}\right) /(\mathrm{ILCT})$ & 454 \\
\hline $1 \mathbf{a}$ & 418 & $\mathrm{~L} \rightarrow \mathrm{H}(90 \%)$ & $\pi^{*}\left(\mathrm{~N}^{\wedge} \mathrm{N}\right) \rightarrow \pi\left(\mathrm{N}^{\wedge} \mathrm{N}\right) /(\mathrm{ILCT})$ & \\
\hline $1 \mathbf{b}$ & 404 & $\mathrm{~L} \rightarrow \mathrm{H}(86 \%)$ & $\pi^{*}\left(\mathrm{~N}^{\wedge} \mathrm{N}\right) \rightarrow \pi\left(\mathrm{N}^{\wedge} \mathrm{N}\right) /(\mathrm{ILCT})$ & \\
\hline $1 \mathrm{c}$ & 411 & $\mathrm{~L} \rightarrow \mathrm{H}(92 \%)$ & $\pi^{*}\left(\mathrm{~N}^{\wedge} \mathrm{N}\right) \rightarrow \pi\left(\mathrm{N}^{\wedge} \mathrm{N}\right) /(\mathrm{ILCT})$ & \\
\hline 2 & 476 & $\mathrm{~L} \rightarrow \mathrm{H}(91 \%)$ & $\begin{array}{l}\pi^{*}\left(\mathrm{~N}^{\wedge} \mathrm{N}\right) \rightarrow \mathrm{d}(\mathrm{Ir})+\pi\left(\mathrm{C}^{\wedge} \mathrm{N}\right) / \\
(\mathrm{MLCT} / \mathrm{LLCT})\end{array}$ & 454 \\
\hline $2 \mathbf{a}$ & 487 & $\mathrm{~L} \rightarrow \mathrm{H}(83 \%)$ & $\begin{array}{l}\pi^{*}\left(\mathrm{~N}^{\wedge} \mathrm{N}\right) \rightarrow \mathrm{d}(\mathrm{Ir})+\pi\left(\mathrm{C}^{\wedge} \mathrm{N}\right) / \\
(\mathrm{MLCT} / \mathrm{LLCT})\end{array}$ & \\
\hline $2 \mathbf{b}$ & 394 & $\mathrm{~L} \rightarrow \mathrm{H}(87 \%)$ & $\begin{array}{l}\pi^{*}\left(\mathrm{~N}^{\wedge} \mathrm{N}\right) \rightarrow \mathrm{d}(\mathrm{Ir})+\pi\left(\mathrm{C}^{\wedge} \mathrm{N}\right) / \\
(\mathrm{MLCT} / \mathrm{LLCT})\end{array}$ & \\
\hline $2 \mathrm{c}$ & 384 & $\mathrm{~L} \rightarrow \mathrm{H}(88 \%)$ & $\begin{array}{l}\pi^{*}\left(\mathrm{~N}^{\wedge} \mathrm{N}\right) \rightarrow \mathrm{d}(\mathrm{Ir})+\pi\left(\mathrm{C}^{\wedge} \mathrm{N}\right) / \\
(\mathrm{MLCT} / \mathrm{LLCT})\end{array}$ & \\
\hline
\end{tabular}

To conveniently discuss the transition property of emission, we list the partial compositions of FMO related to emission in Table S12. $\dagger$ The emission wavelengths are at $479 \mathrm{~nm}$ (for 1), $418 \mathrm{~nm}(1 \mathrm{a}), 476 \mathrm{~nm}$ (2) and $487 \mathrm{~nm}$ (2a), indicating that they are potential candidates for blue-emitting materials. A pronounced red-shift for $2 \mathbf{a}(487 \mathrm{~nm})$ has been observed compared to $2(476 \mathrm{~nm})$, while a relatively larger blue-shift is detected for $\mathbf{2 b}$ (394 $\mathrm{nm}$ ) and $\mathbf{2 c}$ (384 $\mathrm{nm}$ ) compared to own parent. Therefore, $\mathbf{2 b}$ and $\mathbf{2 c}$ might be potential candidates for deep blue-emitting phosphorescent materials. Hence it is seen that the introduction stronger electron-withdrawing group may be an efficient strategy to tune the emitting color of $\mathbf{1}$ and 2 .

Table 2 shows that the lowest-energy emissions of 1-1c originate mainly from LUMO $\rightarrow$ HOMO transition (81-92\%) with characters of the $\pi \rightarrow \pi^{*}$ intraligand ( $\mathrm{N}^{\wedge} \mathrm{N}$ ) charge transfer (ILCT). Specifically, for 2-2c with two triazole ring $\mathrm{N}^{\wedge} \mathrm{N}$ ligand, the lowest-energy emissions (476, 487, 394 and $384 \mathrm{~nm}$, respectively, seen from the Table 2) originate mainly from the HOMO $\rightarrow$ LUMO transition consisting of the mixed MLCT (Ir metal to $\mathrm{N}^{\wedge} \mathrm{N}$ ancillary ligand) and LLCT $\left(\mathrm{C}^{\wedge} \mathrm{N}\right.$ cyclometalated ligands to $\mathrm{N}^{\wedge} \mathrm{N}$ ligand). Thus, the above-mentioned study indicated that either red or blue shifts can be observed by introducing the stronger electron-withdrawing group or changing the ancillary ligand.

\subsection{Quantum efficiency}

There are many parameters that can be used to evaluate the phosphorescent quantum efficiency, such as the d-orbital splitting values and radiative decay rates. In principle, the phosphorescence quantum yield $\Phi_{\mathrm{PL}}$ from an emissive excited state to the ground state is directly related to the radiative $k_{\mathrm{r}}$ and nonradiative $k_{\mathrm{nr}}$ rate constants by eqn (1):

$$
\Phi_{\mathrm{PL}}=\frac{k_{\mathrm{r}}}{k_{\mathrm{r}}+k_{\mathrm{nr}}}
$$

The $k_{\mathrm{nr}}$ from the $\mathrm{T}_{1}$ to the $\mathrm{S}_{0}$ states is usually expressed in the form of the energy law eqn (2), ${ }^{35}$ and the $k_{\mathrm{r}}$ is given by eqn (3): ${ }^{36}$

$$
\begin{gathered}
k_{\mathrm{nr}} \propto \alpha \exp \left(-\beta E_{\mathrm{T}_{1}}\right) \\
k_{\mathrm{r}}=\gamma \frac{\left\langle\Psi_{\mathrm{S}_{1}}\left|H_{\mathrm{S}_{0}}\right| \Psi_{\mathrm{T}_{1}}\right\rangle^{2} \mu_{\mathrm{S}_{1}}{ }^{2}}{\left(\Delta E_{\mathrm{S}_{1}-\mathrm{T}_{1}}\right)^{2}}, \gamma=\frac{16 \pi^{3} 10^{6} n^{3} E_{\mathrm{T}_{1}}{ }^{3}}{3 h \varepsilon_{0}}
\end{gathered}
$$

where $\alpha, \beta$ and $\gamma$ are constant, $\mu_{\mathrm{S}_{1}}$ is the transition electric dipole moment in $\mathrm{S}_{0} \rightarrow \mathrm{S}_{1}$ transition, $E_{\mathrm{T}_{1}}$ represents the emission energy in $\mathrm{cm}^{-1}$, and $n, h$, and $\varepsilon_{0}$ are the refractive index of the medium, Planck's constant, and the permittivity in vacuum, respectively. $\left\langle\Psi_{\mathrm{S}_{1}}\left|H_{\mathrm{S}_{0}}\right| \Psi_{\mathrm{T}_{1}}\right\rangle$ is the spin-orbit couplings (SOC) matrix element. Eqn (2) is well-known as "the energy gap law", ${ }^{35}$ which indicates the $k_{\mathrm{nr}}$ of an excited state increases as the energy difference $\left(E_{\mathrm{T}_{1}}\right)$ between the lowest triplet excited state and the singlet ground state decreases. ${ }^{37}$ On the contrary, eqn (3) shows that $k_{\mathrm{r}}$ increases with the increase of $E_{\mathrm{T}_{1}}$. The presence of a heavy atom Ir is anticipated to increase SOC effects and thus intersystem crossing (ISC), on the condition that its orbitals make a significant contribution to the excited states 
involved. The strength of the SOC interaction can be determined by SOC matrix element between low-lying singlet and triplet states. Therefore, the SOC effects can be firstly elucidated by the metal contribution (MLCT \%) in the $\mathrm{T}_{1}$ state. ${ }^{38}$ Thus, the large MLCT contribution facilitates the increase of $k_{\mathrm{r}}$. In Table 3 , we list the MLCT contributions in the $\mathrm{T}_{1}$ state for the studied complexes.

It is noted that the MLCT \% is found to be affected by the different $\mathrm{N}^{\wedge} \mathrm{N}$ ligand of these complexes. The change of $\mathrm{N}^{\wedge} \mathrm{N}$ ligand, we found that the MLCT for 1-1c has almost vanished. The MLCT of $1(2.43 \%)$ is relatively smaller than that in 2 (24.57\%). The relatively large MLCT contribution is observed in 2 (24.57\%), 2a (21.58\%), 2 b (21.75\%) and 2 c (23.76\%).

On the other hand, the singlet-triplet energy gap $\Delta E_{\mathrm{S}_{1}-\mathrm{T}_{1}}$ also is the factor that affects the SOC effects. ${ }^{39}$ According to eqn (3), transition moment may partially depend on the $\Delta E_{\mathrm{S}_{1}-\mathrm{T}_{1}}$. The ISC rate decreases exponentially as the $\Delta E_{\mathrm{S}_{1}-\mathrm{T}_{1}}$ increases, ${ }^{\mathbf{4 0 - 4 2}}$ a minimal difference between the $\mathrm{S}_{1}-\mathrm{T}_{1}$ splitting energy $\Delta E_{\mathrm{S}_{1}-\mathrm{T}_{1}}$ is favorable for enhancing the ISC rate, leading to an increased $k_{\mathrm{r}}$. Table 3 shows that the $\Delta E_{\mathrm{S}_{1}-\mathrm{T}_{1}}$ for 2 is smaller, and the $\mu_{\mathrm{S}_{1}}$ value, MLCT \% are larger compared with 1. This behavior leads to the contribution to the total ISC rate in a photoluminescence process for complex 2 , and thus a larger $k_{\mathrm{r}}$, which can also not explain their different $\Phi_{\mathrm{PL}}$ for 1 and 2, accordingly, the $k_{\mathrm{nr}}$ is also markedly affected. The designed complexes $\mathbf{2 a}, \mathbf{2 b}$ and $\mathbf{2 c}$ have larger MLCT and smaller $\Delta E_{\mathrm{S}_{1}-\mathrm{T}_{1}}$, and $\mu_{\mathrm{S}_{1}}$ of $\mathbf{2 a}, \mathbf{2} \mathbf{b}$ and $2 \mathbf{c}$ are comparable to that of other structures, therefore it was concluded that the designed complexes $2 \mathbf{a}, \mathbf{2 b}$ and $2 \mathbf{c}$ have a favorable ISC rate which would lead to a higher $k_{\mathrm{r}}$ for them. From the above discussion, it can be concluded that artificial complexes $\mathbf{2 a}, \mathbf{2 b}$ and $\mathbf{2 c}$ with stronger SOC, better ISC rate, and faster radiative decay, may leads to the higher photoluminescent quantum yield $\Phi_{\mathrm{PL}}$ compared to others studied in this paper. However, besides the factors mentioned above, other factors may also play an important role for a high $\Phi_{\mathrm{PL}}$, because $\Phi_{\mathrm{PL}}$ is the competition between $k_{\mathrm{r}}$ and $k_{\mathrm{nr}}$ eqn (1). $k_{\mathrm{nr}}$ is also crucial in controlling a high quantum yield.

It's known that the higher-lying metal-centered $\left({ }^{3} \mathrm{MC} \mathrm{d}-\mathrm{d}\right)$ triplet excited state is considered to be one of the most important deactivation pathways of the phosphorescent emission from $\mathrm{T}_{1}$ state. ${ }^{43-47}$ Theoretically, a larger energy separation between the ${ }^{3} \mathrm{MC} d-\mathrm{d}$ state and the corresponding ${ }^{3} \mathrm{MLCT} / \pi-\pi *$

Table 3 Computed emitting energy $\left(E_{\mathrm{T}_{1}}\right.$ in $\left.\mathrm{eV}\right)$, metal-based charge transfer character (MLCT) (\%), transition dipole moment in the $\mathrm{S}_{0} \rightarrow \mathrm{S}_{1}$ transition $\left(\mu_{\mathrm{S}_{1}}\right)$ (Debye), singlet-triplet splitting energy $\left(\Delta E_{\mathrm{S}_{1}-\mathrm{T}_{1}}\right.$, in $\left.\mathrm{eV}\right)$

\begin{tabular}{lllll}
\hline & $E_{\mathrm{T}_{1}}(\mathrm{eV})$ & $\operatorname{MLCT}(\%)$ & $\mu_{\mathrm{S}_{1}}($ Debye $)$ & $\Delta E_{\mathrm{S}_{1}-\mathrm{T}_{1}}(\mathrm{eV})$ \\
\hline $\mathbf{1}$ & 2.58 & 2.43 & 0.15 & 0.7691 \\
$\mathbf{1 a}$ & 2.96 & 2.70 & 0.30 & 0.1036 \\
$\mathbf{1 b}$ & 3.06 & 2.58 & 0.10 & 0.0539 \\
$\mathbf{1 c}$ & 3.01 & 2.76 & 0.20 & 0.0528 \\
$\mathbf{2}$ & 2.59 & 24.57 & 0.31 & 0.2192 \\
$\mathbf{2 a}$ & 2.54 & 21.58 & 0.31 & 0.1181 \\
2b & 3.14 & 21.75 & 0.33 & 0.0413 \\
2c & 3.22 & 23.76 & 0.32 & 0.0501
\end{tabular}

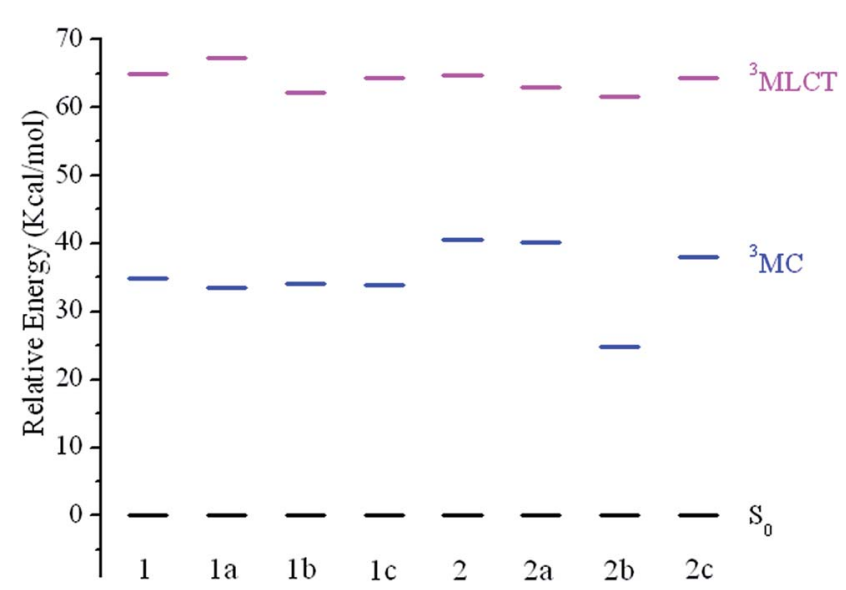

Fig. 5 Energy level diagram of the studied complexes in ${ }^{3}$ MLCT and ${ }^{3} \mathrm{MC}$ excited states, respectively, along with the normalized $\mathrm{S}_{0}$ levels.

emissive state is regarded as an efficient way to reduce nonradiative transition. The ${ }^{3} \mathrm{MLCT} / \pi-\pi^{*}$ excited states were obtained by performing an unrestricted triplet optimization starting from the optimized ground-state geometries, while the electronic configurations of ${ }^{3} \mathrm{MC} \mathrm{d}-\mathrm{d}$ state were calculated starting with a distorted molecular geometries by largely elongating the metal-ligand bonds lengths following the literature. ${ }^{4,49}$ The calculated results are shown in Fig. 5 with the normalized $\mathrm{S}_{0}$ levels.

For all studied complexes, the ${ }^{3} \mathrm{MLCT} / \pi-\pi^{*}$ excited states are lying at a relatively higher energy than that of the ${ }^{3} \mathrm{MC} / \mathrm{d}-$ $\mathrm{d}$ states. This means upon excitation, the ${ }^{3} \mathrm{MC} / \mathrm{d}-\mathrm{d} \rightarrow{ }^{3} \mathrm{MLCT} /$ $\pi-\pi^{*} \rightarrow \mathrm{S}_{0}$ radiation less pathway is expected to be less efficient, which would result in a relatively low $k_{\mathrm{nr}}$. A relationship between the $-\mathrm{CF}_{3}$ substituted $R_{2}$-positions in $\mathrm{N}^{\wedge} \mathrm{N}$ ligand and energy difference between ${ }^{3} \mathrm{MLCT} / \pi-\pi^{*}$ versus ${ }^{3} \mathrm{MC} / \mathrm{d}-\mathrm{d}$ state can be observed (Fig. 5), in which $-\mathrm{CF}_{3}$ substitution remarkable stabilizes the ${ }^{3} \mathrm{MC} / \mathrm{d}-\mathrm{d}$ states for $\mathbf{2 b}$ and $\mathbf{2 c}$ compared with $\mathbf{2}$. The energy of the ${ }^{3} \mathrm{MLCT} / \pi-\pi^{*}$ states only decrease slightly, while the ${ }^{3} \mathrm{MC} / \mathrm{d}-\mathrm{d}$ and ${ }^{3} \mathrm{MLCT} / \pi-\pi^{*}$ states are hardly affected for $\mathbf{1 b}$ and $1 \mathrm{c}$ compared with $\mathbf{1 a}$. As a result, $\mathbf{2 b}$ and $2 \mathrm{c}$ give a larger energy gap between ${ }^{3} \mathrm{MC} / \mathrm{d}-\mathrm{d}$ and ${ }^{3} \mathrm{MLCT} / \pi-\pi *$ states, which would lead to a lower $k_{\mathrm{nr}}$, then a higher emission quantum yield.

\section{Conclusions}

In this article, we have carried out DFT and TDDFT investigations on the structures, spectral properties and phosphorescence efficiency of recently synthesized blue-emitting $\operatorname{Ir}($ III) complexes 1 and 2 and newly designed complexes 1a-1c and 2a2c. The calculated results showed that the substitution pattern does not have much influence on the absorption. It is found that the more $-\mathrm{F}$ and $-\mathrm{CF}_{3}$ groups introduced on the complexes can remarkably stabilize the LUMO energies and then lead to a smaller HOMO-LUMO energy gap. Compared with $\mathbf{1}$ and $\mathbf{2}$, the emission wavelength for $\mathbf{2 a}$ is red-shifted, while they are significantly blue-shifted for $\mathbf{1 a - 1 c}, \mathbf{2 b}$ and $\mathbf{2 c}$. Especially, the emission colour of the complexes $2 \mathbf{b}$ and $2 \mathbf{c}$ are in deep blue 
region. Apart from the lower $S_{1}-T_{1}$ energy gap $\left(\Delta E_{S_{1}-T_{1}}\right)$ and the larger MLCT contributions, the large transition dipole moment $\left(\mu_{\mathrm{S}_{1}}\right)$ and separation between ${ }^{3} \mathrm{MC} / \mathrm{d}-\mathrm{d} \rightarrow{ }^{3} \mathrm{MLCT} / \pi-\pi *$ states may also account for the larger $k_{\mathrm{r}}$ values and are believed to play a key role in maintaining the phosphorescence quantum yield. Mentioned above, on closer inspection of the $\Phi_{\mathrm{PL}}$, complexes $\mathbf{2 b}$ and $2 \mathbf{c}$ with relatively larger $k_{\mathrm{r}}$ and smaller $k_{\mathrm{nr}}$ compared to the others can be attributed to its distinct indirect SOC paths. Thus, the assumed $\mathbf{2 b}$ and $2 \mathbf{c}$ are considered to be potential candidates of deep-blue emitting materials with high quantum efficiency.

\section{Acknowledgements}

The authors thank the Science and Technology Research Project for the Twelfth Five-year Plan of Education Department of Jilin Province of China (Grant No. 2015110 and 201437) and the Program of Science and Technology Development Plan of Jilin Province of China (Grant No. 20140520090JH) and National Natural Science Foundation of China (No. 21401011).

\section{References}

1 W. Y. Wong and C. L. Ho, Coord. Chem. Rev., 2009, 253, 17091758.

2 Y. You and S. Y. Park, Dalton Trans., 2009, 1267-1282.

3 S. Lamansky, P. Djurovich, D. Murphy, F. Abdel-Razaq, H.-E. Lee, C. Adachi, P. E. Burrows, S. R. Forrest and M. E. Thompson, J. Am. Chem. Soc., 2001, 123, 4304-4312.

4 M. A. Baldo, D. F. O'Brien, Y. You, A. Shoustikov, S. Sibley, M. E. Thompson and S. R. Forrest, Nature, 1998, 395, 151154.

5 Highly Efficient OLEDs with Phosphorescent Materials, ed. H. Yersin, Wiley-VCH, Weinheim, Germany, 2008.

6 B. W. D'Andrade and S. R. Forrest, Adv. Mater., 2004, 161, 585-1595.

7 J. Kido, M. Kimura and K. Nagai, Science, 1995, 267, 13321334.

8 Y. Sun, N. C. Giebink, H. Kanno, B. Ma, M. E. Thompson and S. R. Forrest, Nature, 2006, 440, 908-912.

9 K. T. Kamtekar, A. P. Monkman and M. R. Bryce, Adv. Mater., 2010, 22, 72-582.

10 S. Reineke, F. Lindner, G. Schwartz, N. Seidler, K. Walzer, B. Lüssem and K. Leo, Nature, 2009, 459, 234-238.

11 C.-L. Ho and W.-Y. Wong, New J. Chem., 2013, 37, 1665-1683.

12 A. B. Tamayo, S. Garon, T. Sajoto, P. I. Djurovich, I. M. Tsyba, R. Bau and M. E. Thompson, Inorg. Chem., 2005, 44, 87238732.

13 F.-M. Hwang, H.-Y. Chen, P.-S. Chen, C.-S. Liu, Y. Chi, C.-F. Shu, F.-I. Wu, P.-T. Chou, S.-M. Peng and G.-H. Lee, Inorg. Chem., 2005, 44, 1344-1353.

14 T. Matsushita, T. Asada and S. Koseki, J. Phys. Chem. C, 2007, 111, 6897-6903.

15 G. J. Zhou, C. L. Ho, W. Y. Wong, Q. Wang, D. G. Ma, L. X. Wang, Z. Y. Lin, T. B. Marder and A. Beeby, Adv. Funct. Mater., 2008, 18, 499-511.
16 C. Adachi, R. C. Kwong, P. Djurovich, V. Adamovich, M. A. Baldo, M. E. Thompson and S. R. Forrest, Appl. Phys. Lett., 2001, 79, 2082-2084.

17 R. J. Holmes, B. W. D'Andrade, S. R. Forrest, X. Ren, J. Li and M. E. Thompson, Appl. Phys. Lett., 2003, 83, 3818-3820.

18 S.-J. Yeh, W.-F. Wu, C.-T. Chen, Y.-H. Song, Y. Chi, M.-H. Ho, S.-F. Hsu and C.-H. Chen, Adv. Mater., 2005, 17, 285-289.

19 D. Sykes and M. D. Ward, Chem. Commun., 2011, 47, 22792281.

20 P. Hohenberg and W. Kohn, Phys. Rev., 1964, 136, B864B871.

21 J. P. Perdew, K. Burke and M. Ernzerhof, Phys. Rev. Lett., 1996, 77, 3865-3868.

22 J. P. Perdew, K. Burke and M. Ernzerhof, Phys. Rev. Lett., 1997, 78, 1396.

23 A. D. Becke, Phys. Rev. A: At., Mol., Opt. Phys., 1988, 38, 30983100.

24 A. D. Becke, J. Chem. Phys., 1988, 88, 2547-2553.

25 M. M. Francl, W. J. Pietro, W. J. Hehre, J. S. Binkley, M. S. Gordon, D. J. Defrees and J. A. Pople, J. Chem. Phys., 1982, 77, 3654-3665.

26 E. Cances, B. Mennucci and J. Tomasi, J. Chem. Phys., 1997, 107, 3032-3041.

27 M. Cossi, V. Barone, B. Mennucci and J. Tomasi, Chem. Phys. Lett., 1998, 286, 253-260.

28 B. Mennucci and J. Tomasi, J. Chem. Phys., 1997, 106, 51515158.

29 M. J. Frisch, G. W. Trucks, H. B. Schlegel, G. E. Scuseria, M. A. Robb, J. R. Cheeseman, G. Scalmani, V. Barone, B. Mennucci, G. A. Petersson, H. Nakatsuji, M. Caricato, X. Li, H. P. Hratchian, A. F. Izmaylov, J. Bloino, G. Zheng, J. L. Sonnenberg, M. Hada, M. Ehara, K. Toyota, R. Fukuda, J. Hasegawa, M. Ishida, T. Nakajima, Y. Honda, O. Kitao, H. Nakai, T. Vreven, J. A. Montgomery, J. E. Peralta, F. Ogliaro, M. Bearpark, J. J. Heyd, E. Brothers, K. N. Kudin, V. N. Staroverov, R. K. Obayashi, J. Normand, K. Raghavachari, A. Rendell, J. C. Burant, S. S. Iyengar, J. Tomasi, M. Cossi, N. Rega, J. M. Millam, M. Klene, J. E. Knox, J. B. Cross, V. Bakken, C. Adamo, J. Jaramillo, R. Gomperts, R. E. Stratmann, O. Yazyev, A. J. Austin, R. Cammi, C. Pomelli, J. W. Ochterski, R. L. Martin, K. Morokuma, V. G. Zakrzewski, G. A. Voth, P. Salvador, J. J. Dannenberg, S. Dapprich, A. D. Daniels, O. Farkas, J. B. Foresman, J. V. Ortiz, J. Cioslowski and D. J. Fox, Gaussian 09, Revision a 02, Gaussian, Inc, Wallingford CT, 2009.

30 N. M. O'Boyle, A. L. Tenderholt and K. M. Langner, J. Comput. Chem., 2008, 29, 839-845.

31 A. R. Allouche, J. Comput. Chem., 2011, 32, 174-182.

32 A. D. Becke, J. Chem. Phys., 1993, 98, 5648-5652.

33 C. T. Lee, W. T. Yang and R. G. Parr, Phys. Rev. B: Condens. Matter Mater. Phys., 1988, 37, 785-789.

34 A. Dreuw and M. Head-Gordon, J. Am. Chem. Soc., 2004, 126, 4007-4016.

35 J. S. Wilson, N. Chawdhury, M. R. A. Al-Mandhary, M. Younus, M. S. Khan, P. R. Raithby, A. Kohler and R. H. Friend, J. Am. Chem. Soc., 2001, 123, 9412-9417. 
36 S. Haneder, E. D. Como, J. Feldmann, J. M. Lupton, C. Lennartz, P. Erk, E. Fuchs, O. Molt, I. M€unster, C. Schildknecht and G. Wagenblast, Adv. Mater., 2008, 20, 3325-3330.

37 L. L. Shi, J. J. Su and Z. J. Wu, Inorg. Chem., 2011, 50, 54775484.

38 J.-D. Chai and M. Head-Gordon, Phys. Chem. Chem. Phys., 2008, 10, 6615-6620.

39 I. Avilov, P. Minoofar, J. Cornil and L. De Cola, J. Am. Chem. Soc., 2007, 129, 8247-8258.

40 G. Gigli, F. Della Sala, M. Lomascolo, M. Anni, G. Barbarella, A. Di Carlo, P. Lugli and R. Cingolani, Phys. Rev. Lett., 2001, 86, 167-170.

41 D. Beljonne, J. Cornil, R. H. Friend, R. A. J. Janssen and J. L. Brédas, J. Am. Chem. Soc., 1996, 118, 6453-6461.

42 A. L. Burin and M. A. Ratner, J. Chem. Phys., 1998, 109, 60926102.
43 G. Treboux, J. Mizukami, M. Yabe and S. Nakamura, Chem. Lett. , 2007, 36, 1344-1345.

44 F. Alary, J. L. Heully, L. Bijeire and P. Vicendo, Inorg. Chem., 2007, 46, 3154-3165.

45 J. Van Houten and R. J. Watts, J. Am. Chem. Soc., 1976, 98, 4853-4858.

46 T. Sajoto, I. Djurovich, A. B. Tamayo, J. Oxgaard, W. A. Goddard and M. E. Thompson, J. Am. Chem. Soc., 2009, 131, 9813-9822.

47 D. M. Roundhill, Photochemistry and Photophysics of Metal Complexes, Plenum Press, New York, 1994.

48 T. Bark and R. P. Thummel, Inorg. Chem., 2005, 44, 87338739.

49 M. Abrahamsson, M. J. Lundqvist, H. Wolpher, O. Johansson, L. Eriksson, J. Bergquist, T. Rasmussen, H.-C. Becker, L. Hammarström, P.-O. Norrby, B. Åkermark and P. Persson, Inorg. Chem., 2008, 47, 3540-3542. 